\title{
Timpanik Membran Anterior Perforasyonu Olan Hastalarda Endoskopik Kıkırdak Timpanoplasti Sonuçlarımız
}

\section{Our Results of Endoscopic Cartilage Tympanoplasty in Patients with Tympanic Membrane Anterior Perforation}

\author{
Secaattin GÜLŞEN 1 (D), Sercan CIKRIKCI 2 (1)
}

\author{
1 Dr. Ersin Arslan Eğitim ve Araştırma Hastanesi, Kulak Burun Boğaz Kliniği, Gaziantep, Türkiye \\ 2 Yozgat Şehir Hastanesi, Kulak Burun Boğaz Kliniği, Yozgat, Türkiye
}

Öz.

Amaç: Birçok greftleme tekniği ve cerrahi yaklaşım tanımlanmasına rağmen timpanik membran anterior kadran perforasyonlarının onarımı teknik olarak kulak burun boğaz uzmanları için zorlayıcıdır. Bu çalışmada, timpanik membran anterior kadran perforasyonlarının onarımında endoskopik kıkırdak timpanoplastinin cerrahi ve fonksiyonel sonuçlarının değerlendirilmesi amaçlanmıştır.

Materyal ve metod: 1 Ocak 2015- 30 Nisan 2019 tarihleri arasında anterior kadran perforasyonu olan ve transkanal endoskopik Tip 1 kıkırdak timpanoplasti yapılan 34 hasta çalışmaya alındı. Bu hastaların greft başarısı, odyolojik verileri ve komplikasyonlar geriye dönük olarak incelendi. Kemikçik zincir rekonstrüksiyonu yapılan, kolesteatomu olan veya takiplerine düzenli gelmeyen hastalar ve timpanik membran perforasyonu anterior kadranda olmayan hastalar çalışma dışı bırakıldı.

Bulgular: Endoskopik transkanal kıkırdak timpanoplasti yapılan 34 hastanın tıbbi kayıtları incelendi. 15 erkek $(\% 44,1)$ ve 19 kadın $(\% 55,9)$ hasta vardı. Ortalama yaş 35,44 $\pm 9,84$ 'dü. Hastaların 15 'i sağ kulak $(\% 44,1), 19$ 'u sol kulaktan $(\% 55,9)$ ameliyat oldu. Ortalama ameliyat süresi $31,56 \pm 4,04$ dakikaydı. Greft başarı oranları postoperatif 3. Ayda $\% 94,1$ ve postoperatif 6 . Ayda $\% 91,2$ idi. Ameliyat sonrası altıncı ayda yapılan saf ses odyometri ölçümlerine göre postoperatif hava-kemik aralığı değerleri, preoperatif değerlere göre istatistiksel olarak anlamlı derecede düzeldi $(p<0,001)$.

Sonuç: Endoskopik transkanal Tip 1 kıkırdak timpanoplasti timpanik membran anterior perforasyonlarını onarmak için minimal invaziv, etkili ve güvenilir bir cerrahi tedavi seçeneğidir.

Anahtar Kelimeler: Kulak zarı, Perforasyon, Anterior, Endoskop, Kıkırdak, Timpanoplasti

Abstract

Background: Although many grafting techniques and surgical approaches have been described, repair of tympanic membrane anterior quadrant perforations is technically challenging for otorhinolaryngology specialists. In this study, it was aimed to evaluate the surgical and functional results of endoscopic cartilage tympanoplasty in repair of tympanic membrane anterior quadrant perforations.

Materials and Methods: Thirty-four patients who had anterior quadrant tympanic membrane perforation and underwent transcanal endoscopic Type 1 cartilage tympanoplasty between January 1, 2015 and April 30, 2019 were included in the study. The graft success, audiological data and complications of patients were retrospectively analyzed. Patients who had ossicular chain reconstruction, who had cholesteatoma or who did not have regular follow-up and those whose tympanic membrane perforation was not in the anterior quadrant were excluded. Results: Medical records of 34 patients who underwent endoscopic transcanal cartilage tympanoplasty were examined. There were 15 male (44,1\%) and 19 female (55,9\%) patients. The average age was 35,44 $\pm 9,84$. Fifteen of the patients underwent surgery on the right ear (44.1\%) and 19 on the left ear (55,9\%). The mean operation time was $31.56 \pm 4.04$ minutes. Graft success rates were $94,1 \%$ in the 3rd postoperative month and $91,2 \%$ in the 6 th postoperative month. Postoperative air-bone gap values improved statistically significantly compared to preoperative values according to the pure tone audiometry measurements performed at the sixth month after surgery $(p<0,001)$.

Conclusion: Endoscopic transcanal Type 1 cartilage tympanoplasty is a minimally invasive, effective and reliable surgical treatment option to repair tympanic membrane anterior perforations.

Key words: Tympanic membrane, Perforation, Anterior, Endoscope, Cartilage, Tympanoplasty

\section{Sorumlu Yazar I \\ Corresponding Author}

Op. Dr. Sercan ÇIKRIKCI

Yozgat Şehir Hastanesi, Kulak Burun Boğaz Kliniği, Erdoğan Akdağ Mah., Viyana Cad. Yozgat Şehir Hastanesi 66100 Merkez/Yozgat

e-mail: drsrc46@gmail.com

Tel: 03542190010

Faks: 03545020301

Geliş tarihi / Received: 16.03.2020

Kabul tarihi / Accepted: 07.12.2020

DOI: 10.35440/hutfd.704151 


\section{Giriş}

Endoskopi otoloji pratiğinde önceleri sadece kulak muayenesi için kullanılırken son yıllarda otolojik cerrahide primer ya da yardımcı cihazlar olarak sıkça kullanılmaya başlanmıştır. Orta kulak cerrahisinde geleneksel mikroskopik yaklaşım halen en yaygın kullanılan tekniktir $(1,2)$. Mikroskobun lineer görüş alanı, orta kulaktaki anterior attik, fasiyal reses, sinüs timpani gibi saklı bölgelerin görüntülenmesini önler $(1,2)$. Buna karşın, endoskoplar geniş bir görüş alanı sağlar, cerrahın görüş açısının hızlıca ayarlanmasını sağlar ve girintileri, anterior marjinal perforasyonları ve sinüs timpani gibi mikroskopik yaklaşımda görüntülenmesi zor alanların ek cerrahi işlem yapılmaksızın kolayca görüntülenmesini sağlar $(1,2)$.

Endoskopik transkanal yaklaşım ile miringoplasti, ossiküloplasti, otoskleroz cerrahisi gibi birçok kulak ameliyatı yapılabilir. Öte yandan, endoskoplar mikroskopik yaklaşımların yetersiz kaldığı noktalarda yardımcı cihaz olarakta kullanılabilir. Endoskopik kulak cerrahisinin tek elle çalışma, uzamış öğrenme eğrisi ve derinlik algısının olmaması gibi dezavantajları olmasına rağmen, endoskopların geniş görüş açıSı, timpanik membran (TM) tüm kadranlarının ve orta kulak yapılarının herhangi bir manevra yapılmadan görüntülenmesini mümkün kılar $(1,3)$. Bu çalışmadaki amacımız, kronik otitis media nedeniyle TM anterior kadran perforasyonu olan ve endoskopik transkanal kıkırdak timpanoplasti yapılan hastalarının cerrahi ve fonksiyonel sonuçlarını analiz etmektir.

\section{Materyal ve Metod}

1 Ocak 2015- 30 Nisan 2019 tarihleri arasında TM anterior perforasyonu olan ve transkanal endoskopik Tip 1 kıkırdak timpanoplasti yapılan 34 hasta çalışmaya dahil edilmiştir. $\mathrm{Bu}$ hastaların greft başarı oranları ve odyolojik sonuçları incelendi. Kemikçik zincir rekonstrüksiyonu yapılan, kolesteatomu olan, TM perforasyonu anterior kadranda bulunmayan ve takiplerine düzenli gelmeyen hastalar çalışma dışı bırakıldı. Mevcut çalışmayı Bozok Üniversitesi klinik araştırmalar etik kurulu 2017-KAEK-189_2019.09.11_01 karar numarası ile onaylamıştır.

Ameliyat öncesi otoskopik muayenede manibrium malleinin ve buna paralel olarak çizilen çizginin önünde kalan perforasyonlar TM anterior kadran perforasyonları olarak tanımlandı. Ameliyat sonrası birinci ay ve 6 . ayda greft başarı oranlarını tespit etmek için hastalar kontrole çağııııdı. Ameliyat sonrası altıncı ayda greft perforasyonu, lateralizasyonu veya medializasyonu olmayan hastalarda greft başarılı olarak kabul edildi. Preoperatif, postoperatif 1. ay ve postoperatif 6 . ayda saf ses odyometri (SSO) sonuçları karşılaştııılı. Hastaların SSO değerleri hesaplanırken $500,1000,2000$ ve $4000 \mathrm{~Hz}$ frekanslarında yapılan eşik ölçümlerinin ortalaması alındı. Hava - kemik yolu aralığı $(\mathrm{HKA})$, hava yolu eşikleri (HYE) ve kemik yolu eşikleri
(KYE) karşılaştııılı. Ameliyat süresi olarak lokal anestezinin başlangıcından yara pansumanının sonuna kadar olan süre hesaplandı. Ameliyat anında ve sonrasında takip süresi boyunca erken ve geç dönemde gelişen tüm komplikasyonlar kayıt altına alındı ve geriye dönük olarak incelendi.

\section{Cerrahi Prosedür}

Tüm cerrahi işlemler genel anestezi altında aynı cerrah tarafından yapıımıştır. Hastalarda kanamayı azaltmak için Lidokain $\mathrm{HCl}(\% 2)$ ve Epinefrin (\%0.125) içeren lokal anestezik ajan (Jetokain, Adeka, Samsun, Türkiye) dış kulak yoluna infiltre edildi. Greft olarak tragustan alınan kompozit kondro-perikondriyal greft kullanıldı ve kıkırdak dokusu yaklaşık 0.2-0.5 mm kalınlığı aralığında inceltildi. Transkanal endoskopik timpanoplasti prosedürlerinde $18 \mathrm{~cm}$ uzunluğunda, 4 veya $2.7 \mathrm{~mm}$ çapında $0^{\circ}$ rijid endoskoplar (Karl Storz, Tutlingen, Almanya) kullanıldı. TM perforasyon kenarları eğri pik yardımıyla desepitelize edildi (Şekil 1).

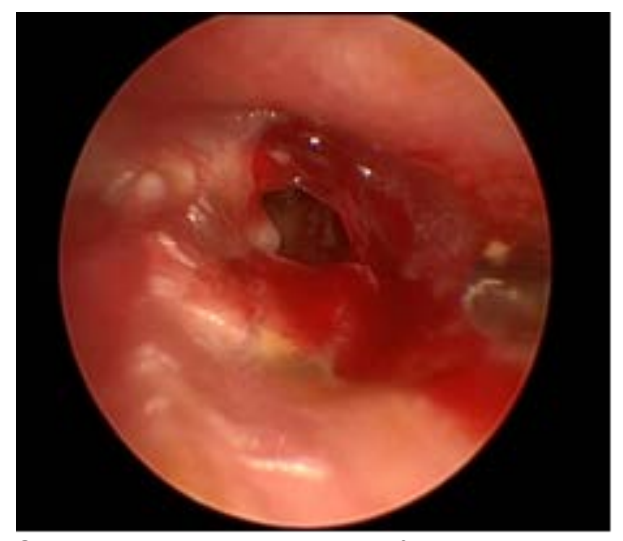

Şekil 1. Anterior yerleşimli perforasyon

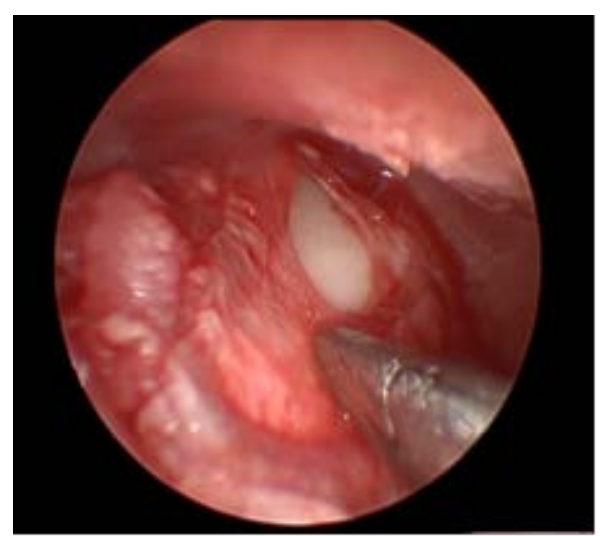

Şekil 2. Tragal greft ile perforasyonun kapatılması

Anulusun yaklaşık 5-10 mm lateralinden saat 6 ve 12 hizasında klasik Rosen insizyon yapılarak timpanomeatal flep eleve edildi. Korda timpani siniri korunarak anulusun altından orta kulağa girildi. Manibrium mallei diseksiyonu yapılarak underlay greftleme için destek oluşturuldu ve kemikçik zincir bütünüyle ortaya konuldu. Orta kulak mukozası ve kemikçik zincir mobilizasyonu değerlendirildi. Daha sonra tragustan alınan kompozit kondro-perikondriyal greft 
underlay tekniği ile yerleştirildi (Şekil 2). Orta kulak Gelfoam (Pfizer Inc. Newyork, USA) ile desteklendi ve timpanomeatal flep tekrar dış kulak yoluna yatııldı. Perforasyonun greft ile tam olarak kapandığı görüldükten sonra dış kulak yolu da Gelfoam ile dolduruldu ve pansuman yapılarak ameliyat sonlandırılı. Endoskopik transkanal timpanoplasti yapılan tüm hastalar aynı gün taburcu edildi. Hastalara taburculuk sonrası 1 hafta boyunca kullanılmak üzere oral amoksisilin-klavunat reçete edildi, penisilin alerjisi olan hastalara klaritromisin reçete edildi. Ameliyat sonrası yedinci gün de pansuman açılıp siprofloksasin (Siprogut damla, Bilim, İstanbul, Türkiye) ve deksametazon (Onadron damla, I.E. Ulugay, Türkiye) içeren kulak damlaları 2 hafta kullanılmak suretiyle başlandı.

\section{İstatiksel Analiz}

İstatiksel analizler için Windows 10 için SPSS paket programı (versiyon 22.0) kullanıldı. Sürekli değişkenlerin normal dağılım gösterip göstermediği Kolmogorov-Smirnov testi ile analiz edildi. Sürekli veriler ortalama \pm standart sapma şeklinde, kategorik veriler ise sayı ve yüzde şeklinde ifade edildi. İşlem öncesi ve işlem sonrası tekrarlayan sürekli verilerin karşılaştırılmasında tekrarlayan ölçümlerde ANOVA testi kullanıldı. P değerinin 0,05 değerinden düşük olması istatiksel olarak anlamlı kabul edildi.

\section{Bulgular}

Endoskopik transkanal kıkırdak timpanoplasti yapılan 34 hastanın tıbbi kayıtları geriye dönük olarak incelendi. 15 erkek $(\% 44,1)$ ve 19 kadın $(\% 55,9)$ hasta vardı. Ortalama yaş 35,44 $\pm 9,84$ idi. Ameliyat yönü olarak hastaların $15{ }^{\prime} i$ sağ kulak (\%44,1), 19'u sol kulaktı (\%55,9). Perforasyon alanının genişliği $5(\% 14,7)$ hasta da $\% 25,29(\% 85,3)$ hasta da \%25-50 arasinda idi (Tablo 1).

Ortalama ameliyat süresi 31,56 $\pm 4,04$ dakikaydı. Postoperatif dönemde greft başarısı 3.ayda \%94,1 (34 kulaktan 32'si) ve 6.ayda \%91,1 (34 hastada 31) idi (Tablo 1).

Tablo 1. Hastaların demografik verileri

\begin{tabular}{|l|l|l|}
\hline Parametreler & Sayı & Yüzde\% \\
\hline Cinsiyet & & \\
Erkek & 15 & 44.1 \\
Kadın & 19 & 55.9 \\
\hline Yön & & \\
Sağ & 15 & 44.1 \\
Sol & 19 & 55.9 \\
\hline Postoperatif 3. ayda greft başarıIı & & \\
Başarııız & 2 & 5.9 \\
Başarııı & 32 & 94.1 \\
\hline Postoperatif 6. Ayda greft başarısı & & \\
Başarııız & 3 & 8.8 \\
Başarııı & 31 & 91.2 \\
\hline
\end{tabular}

n: hasta sayısI

Preoperatif dönemde SSO ölçümlerinde HYE ortalaması $24 \pm 3,5 \mathrm{~dB}$ idi. Postoperatif birinci ve altıncı aylarda (sırasıyla 7,82 $\pm 2,60$ ve $7,06 \pm 2,65 \mathrm{~dB}$ ) HKA değerlerinin aşa- malı olarak anlamlı şekilde düzeldiği tespit edildi. Preoperatif HKA ortalaması 16,21 $\pm 3,46 \mathrm{~dB}$ idi. Benzer şekilde, postoperatif birinci $(15,38 \pm 2,59 \mathrm{~dB})$ ve altıncı aylarda $(14,12 \pm 2,65 \mathrm{~dB})$ SSO ölçümlerinde HYE değerlerinin anlamlı olarak düzeldiği görüldü (Tablo 2).

Tablo 2. Preoperatif ve postoperatif işitme sonuçları

\begin{tabular}{|l|l|l|l|l|l|l|}
\hline & Preoperatif & $\begin{array}{l}\text { Postoperatif } \\
\text { 1. ay }\end{array}$ & $\begin{array}{l}\text { Postoperatif } \\
\text { 6. ay }\end{array}$ & P1 & P2 & P3 \\
\hline $\begin{array}{l}\text { HYE, } \\
\text { dB }\end{array}$ & $24 \pm 3,5$ & $15,38 \pm 2,59$ & $14,12 \pm 2,34$ & $<0,001$ & $<0,001$ & $<0,001$ \\
\hline $\begin{array}{l}\text { KYE, } \\
\text { dB }\end{array}$ & $7,79 \pm 1,53$ & $7,56 \pm 1,26$ & $7,06 \pm 0,98$ & 0,058 & 0,006 & 0,027 \\
\hline $\begin{array}{l}\text { HKA } \\
\text { dB }\end{array}$ & $16,21 \pm 3,46$ & $7,82 \pm 2,60$ & $7,06 \pm 2,65$ & 0,000 & 0,000 & 0,022 \\
\hline
\end{tabular}

HYE: hava yolu eşikleri, KYE: kemik yolu eşikleri, HKA: hava kemik aralığı dB: desibel

P1: Preoperatif ve Postoperatif 1. Ay karşılaştırması

P2: Preoperatif ve Postoperatif 6. Ay karşılaştırması

P3: Postoperatif 1. Ay ve Postoperatif 6. Ay karşılaştırması $p<0,05$ ise istatistiksel olarak anlamlıdır.

Postoperatif dönemde sensörinöral işitme kaybı, kemikçik zincir hasarı, fasial paralizi gibi majör komplikasyon görülmedi. $4(\% 11,7)$ hastada korda timpani sinirinin aşırı manipulasyonyla ilişkili olabilecek postoperatif dönemde geçici tad alma duyusunda bozulma gelişti. Tüm hastalarda tat alma duyusunda meydana gelen bozulma en geç 3 ay içinde kendiliğinden düzeldi. Postoperatif altı aylık takipleri sırasında $5(\% 14,7)$ hastada otore-eksternal otit gelişti. Bu beş hastanın üçünde $(\% 8,8)$ reperforasyon gelişti.

\section{Tartışma}

$\mathrm{AA}$, birçok etiyolojik sebebleri olmasına rağmen genellikle TM perforasyonlarının endoskopik transkanal yaklaşımla onarımı dünya çapında gittikçe popülerlik kazanmaktadır. Kulak cerrahisinde mikroskopik ve endoskopik yaklaşım arasındaki en önemli fark endoskopların sağladığı geniş görüş açısı ve mikroskopla doğrudan görülemeyen orta kulaktaki saklı alanların kolayca görüntüleme olanağıdır (47). Tarabichi ve arkadaşları mikroskopik cerrahi sırasındaki görüşün, kulak kanalının en dar kesimi tarafından sınırlandıııldığını bildirmiştir $(8,9)$. Buna karşıık, transkanal endoskopik yaklaşımla kulak kanalının en dar bölümünü bypas edilmiş olur ve kanalplasti yapılmadan orta kulak cerrahisi yapılabilir. Literatürde timpanoplastide mikroskobik ve endoskopik görüntüleri karşılaştırmak için çeşitli çaIışmalar yürütülmüştür (10-12). Mikroskopi gruplarında, timpanik anulusun, hastaların \%17 ile \%20'sinde tamamen görselleştirilmediğini ve bu nedenle kanaloplasti gerektirdiğini bildirmişlerdir (10-12). Bununla birlikte endoskopi gruplarında timpanik anulus tamamen görselleştirimiş; bu nedenle, hiçbir hastaya kanaloplasti yapılması gerekmemiş (10-12). Ayache ve arkadaşları, TM anterior perforasyon nedeni ile timpanoplasti yapılan hastalarda mikroskopik yaklaşımda $\% 73$ hastada perforasyonun anterior kenarının tamamen görüntülenemediğini bildirmiştir (13). Bizim çalış- 
mamızda ise TM perforasyonlarının anterior sınırını görselleştirmek için hiçbir hastada kanaloplasti prosedürüne ihtiyaç duyulmadı. Bu çalışmalar doğrultusunda, özellikle dış kulak yolu anterior duvarı prominent olan ve TM anterior kadran perforasyonu olan hastalarda endoskopik yaklaşımın tartışmasız bir şekilde mikroskopik yaklaşımdan daha üstün olduğu açıktır.

Otolojik cerrahi pratiğinde, endoskopik yaklaşım mikroskopik yaklaşımla karşılaştıııldığında tek elle çalışma, kanama ve buğulanmaya bağlı görüntüde bozulma ve uzamış öğrenme eğrisi gibi bazı dezavantajlara sahiptir $(8,9,14)$. Düşük ve stabil preoperatif ve intra-operatif arteryel kan basıncı, dış kulak yoluna lokal anestezik ajan infiltrasyonu ve endoskopik kulak cerrahisi için modifiye edilmiş aspirasyon fonksiyonlu otolojik cerrahi aletlerin kullanımı gibi bazı yakIaşımlarla endoskopik kulak cerrahi sırasında karşılaşılabilen ve ameliyat süresini uzatan kanamalar önlenebilir $(13,15)$.

Literatürdeki çalışmalara bakıldığında, TM anterior perforasyonu olan hastalarda yapılan endoskopik transkanal timpanoplastilerin ortalama ameliyat süreleri 37-66.1 dakika arasında değişmektedir $(5,16)$. Bizim çalışmamızda ise ortalama ameliyat süresi 31.56 dakika olarak bulundu. Literatürde TM anterior perforasyonlu olgularda mikroskopik yaklaşımla yapılan timpanoplasti sonrası greft başarı oranı \%88 ile \%98 arasında bildirilmiştir (17-20). Öte yandan TM anterior perforasyonlarda endoskopik timpanoplasti yapılan hastalarda ise greft başarı oranları $\% 87$ ile \%93 arasında değişmektedir (5-7). Bizim çalışmamızın greft başarı sonuçları literatürle uyumlu olup, ameliyat sonrası altıncı aydaki greft başarı oranı $\% 91,2$ idi.

Yapılan çeşitli çalışmalarda, yaş, perforasyon lokasyonu, perforasyon büyüklügü, postoperatif otore, revizyon cerrahisi ve perforasyon marjının zayıf görselleştirilmesi gibi çeşitli faktörlerin myringoplasti başarısını etkilediği ortaya konulmuştur $(4,20,21)$. Tseng ve arkadaşları postoperatif otoresi olan hastaların greft başarı oranlarının postoperatif otore olmayan hastalarınkine göre anlamlı derecede daha düşük olduğunu belirtmiştir (5). Yine aynı çalışmada otoreye kontrolsüz preoperatif enfeksiyonların veya postoperatif enfeksiyonların neden olabileceğini belirtilmiştir. Literatürdeki makalelerde TM perforasyon anterior sınırının kanalplasti yapılmadan tam olarak görüntülenemediği olguların ameliyat süresi, perforasyon kenarlarının tam olarak görüntülenebildiği olgulara kıyasla anlamlı derecede daha uzun saptanmıştır $(4,5)$. Buna karşın, TM perforasyon sınırlarının tam veya kısmi görüntülenebilmesinin greft başarısı üzerine herhangi bir etkisinin olmadığı bildirilmiştir $(4,5)$.

Nassif ve arkadaşları pediatrik hastalardaki mikroskopik ve endoskopik timpanoplasti yöntemlerini karşılaştırdıkları çaIışmalarında; her iki grubun SSO sonuçları, işitme sonuçlarında düzelme olduğunu göstermiştir; ayrıca HKA değerleri mikroskopik yöntemde $6.2 \mathrm{~dB}$, endoskopik yöntemde
6.6dB azaldığını bildirmiştir. Bu çalışmada araştırmacılar endoskopik yöntemin hem işitme yararı hem de anatomik iyileşme için daha güvenilir olduğu ve yaştan bağımsız tüm hastalara uygulanabileceği sonucuna varmışlar (22). Kaya ve arkadaşları kronik otitis mediası olan ve kıkırdak timpanoplasti yapılan 93 hastadan oluşan seride preoperatif hava yolu işitme eşiklerinin postoperatif 6.aydakine göre anlamlı derecede azaldığını bildirmiştir (23). Ayache ve arkadaşları endoskopik miringoplasti yaptığı 30 hastalık seride hava-kemik yolu aralığı değerinin ortalama \%55 (2981 arasında değişmekte) ile 17,7'den 7,9 dB'ye düştüğünü bildirmiştir (13). Bizim çalışmamızda literatürle örtüşmekte olup, postoperatif dönemde SSO ölçümlerinde anlamlı $(P<0,001)$ derecede düzelme olduğunu göstermiştir.

\section{Sonuç}

Kanaloplasti gerektirmeden TM anterior perforasyonlarının anterior sınırını göstermede endoskopik yaklaşım tarış̧ımaz üstünlük sunar. Daha kısa ameliyat süresi, ameliyat sonrası azalmış morbidite ve hızı ıyileşme süresi endoskopik yaklaşımın avantajları arasındadır. Anterior kadran yerleşimli TM perforasyonlarının onarımında minimal invazif bir cerrahi teknik olan endoskopik transkanal timpanoplasti, karşılaşıııılabilir greft başarı oranları ve odyolojik sonuçlarıyla makul ve etkili alternatif bir yaklaşımdır.

Etik onam: Çalışmanın için etik onam Bozok Üniversitesi klinik araştırmalar etik kurulundan 11/09/2019 tarihinde 2017-KAEK-189_2019.09.11_01 karar numarası ile alınmıştır.

\section{Kaynaklar}

1. Kakehata S, Futai K, Sasaki A, Shinkawa H. Endoscopic transtympanic tympanoplasty in the treatment of conductive hearing loss: early results. Otol Neurotol. 2006; 27(1):14-9.

2. Yadav SP, Aggarwal N, Julaha M, Goel A. Endoscope-assisted myringoplasty. Singapore Med J. 2009; 50(5):510-2.

3. Mohindra S, Panda NK. Ear surgery without microscope; is it possible. Indian J Otolaryngol Head Neck Surg. 2010; 62(2):138-41.

4. Pinar E, Sadullahoglu K, Calli C, Oncel S. Evaluation of prognostic factors and middle ear risk index in tympanoplasty. Otolaryngol Head Neck Surg. 2008;139(3):386-90.

5. Tseng CC, Lai MT, Wu CC, Yuan SP, Ding YF. Endoscopic transcanal myringoplasty for anterior perforations of the tympanic membrane. JAMA Otolaryngol Head Neck Surg. 2016; 142(11):1088-93.

6. Celik H, Samim E, Oztuna D. Endoscopic "push-trough": technique cartilage myringoplasty in anterior tympanic membrane perforations. Clin Exp Otorhinolaryngol. 2015; 8(3):224-9.

7. Visvanathan $V$, Vallamkondu V , Bhimrao SK. Achieving a Successful Closure of an Anterior Tympanic Membrane Perforation: Evidence-Based Systematic Review. Otolaryngol Head Neck Surg. 2018;158(6):1011-15.

8. Tarabichi M. Endoscopic middle ear surgery. Ann Otol Rhinol Laryngol. 1999;108(1):39-46.

9. Tarabichi M, Ayache S, Nogueira JF, Al Qahtani M, Pothier DD. Endoscopic management of chronic otitis media and tympanoplasty. Otolaryngol Clin North Am. 2013;46(2):155-63.

10. Furukawa T, Watanabe T, Ito T, Kubota T, Kakehata S. Feasibility and advantages of transcanal endoscopic myringoplasty. Otol Neurotol. 2014; 35(4):140-5.

11. Lade $H$, Choudhary SR, Vashishth A. Endoscopic vs microscopic 
myringoplasty: a different perspective. Eur Arch Otorhinolaryngol. 2014; 271(7):1897-902.

12. Harugop AS, Mudhol RS, Godhi RA. A comparative study of endoscope assisted myringoplasty and micrsoscope assisted myringoplasty. Indian J Otolaryngol Head Neck Surg. 2008; 60(4):298-302.

13. Ayache S. Cartilaginous myringoplasty: the endoscopic transcanal procedure. Eur Arch Otorhinolaryngol. 2013; 270(3):853-60.

14. Karhuketo TS, llomäki JH, Puhakka HJ. Tympanoscope-assisted myringoplasty. ORL J Otorhinolaryngol Relat Spec. 2001; 63(6):353-7. 15. Ayache S, Beltran M, Guevara N. Endoscopic transcanal myringoplasty for anterior tympanic membrane perforation. Eur Ann Otorhinolaryngol Head Neck Dis. 2019;136(5): 413-5.

16. El-Hennawi DEM , Ahmed MR , Abou-Halawa AS , El-Hamtary MA. Endoscopic push-through technique compared to microscopic underlay myringoplasty in anterior tympanic membrane perforations. J Laryngol Otol. 2018;132(6):509-13.

17. Schraff S, Dash N, Strasnick B. "Window shade" tympanoplasty for anterior marginal perforations. Laryngoscope. 2005;115(9):1655-9.

18. Peng R, Lalwani AK. Efficacy of "hammock" tympanoplasty in the treatment of anterior perforations. Laryngoscope. 2013;123(5):1236-40. 19. Seidman MD. Anterior transcanal tympanoplasty: a novel technique to repair anterior perforations. Otolaryngol Head Neck Surg. 2008; 138(2):242-5.

20. Lee HY, Auo HJ, Kang JM. Loop overlay tympanoplasty for anterior or subtotal perforations. Auris Nasus Larynx. 2010; 37 (2): 162-6.

21. Nardone M, Sommerville R, Bowman J, Danesi G. Myringoplasty in simple chronic otitis media: critical analysis of long-term results in a 1000-adult patient series. Otol Neurotol. 2012; 33(1):48-53.

22. Nassif N, Berlucchi M, de Zinis LO. Tympanic membrane perforation in children: endoscopic type I tympanoplasty, a newly technique, is it worthwhile? Int J Pediatr Otorhinolaryngol. 2015; 79(11):1860-4.

23. Kaya I, Benzer M, Uslu M, Bilgen C, Kirazli T. Butterfly cartilage tympanoplasty long-term results: excellent treatment method in small and medium sized perforations. Clin Exp Otorhinolaryngol. 2018;11(1):23-9. 